\title{
NOTAS ETIMOLÓGICAS
}

\author{
R.F. Mansur Guérios \\ Professor emérito da UFPR
}

\section{RESUNO}

Novas pesquisas etimológicas, cujos resultados serão incluidos em futura ediçāo do DICIONÁRIO DE ETIMOLOGIAS DA LINGUA PORTUGUESA do Autor, têm estes titulos: CONSUL, PESSOA, LUZIR, BRANCO, LADAINHA, PONEI, EXPLICAR, FELINO, LITURGIA, FEIJĀO, FIL(O)-, RUBEOLA, PRUDENTE, ATACADO, ALFACE, VICIO, SU. FRAGIO, PRETO, SACRÁRIO, TREMER, OSCULO, PARPALHAÇA, CLERO, PREMIO, CASTO, LATIM, GUAI!, ARTE, CAVALO, GUERRILHA, INSTRUMENTALISMO, BATIZAR, ESTRADA, PIPOCA, MINISTRO, PANTERA, PALHETE, ATROZ, POLICIA, -LENTO, ESPIRITO, CHOU. PO, CARNAVAL, PEDRA, ISCA, CARO, LONGINQUO, IMBUIR, PROFETA, DERRUBAR, DERRIBAR, MISTICO, UVVULA, INTERVALO, ACOSSAR, ANJO, VIRTUDE,

CONSUL - E o lat. CONSUL (lat. arc. CONSOL, CO. SOL), nome dado a cada um dos dois primeiros magistrados romanos, após a queda da realeza (510 a.C.). Tais foram Lucius Iunius Brutus e Lucius Tarquinius Collatinus.

A criação de dois cônsules tinha por fim contrabalançar a sua autoridade; nenhum podia atentar contra a liberdade sem ser reprimido pelo outro.

No princípio só os patricios podiam ser cônsules; os plebeus, depois de 367 a.C. Eram eleitos, por um ano, pelas COMITIA CENTURIATA, "assembléias de centúrias", de cen membros. Sua posse era cerimoniosa: uma procissão ao Capitólio, e um sacrificio a Júpiter (CôNSUL chegou a ser epiteto desta divindade).

Grandes eram seus encargos: chefia do exército, regulamentação da guerra e da paz, centralização da justiça e do 
tesouro nacional, convocação do senado, convocação do povo para nomeaçōes, promulgações das leis. Tinham o direito de vida e morte dentro dos limites de uma milha 20 redor de Roma. Suas insignias eram a toga pretexta e a cadeira curul.

Designavam-se os anos pelo nome de um dos cônsules. Diz Horácio, falando a uma ânfora: O NATA MECUM CONSULE MANLIO, ó (ânfora) nascida comigo no consulado de Mânlio (ODE, III, 21).

$\mathrm{Na}$ Idade Média dava-se o nome CôNSUL a funcionário mantido pelo Estado em outro pais, a fim de supervisionar as transações comerciais. Logo passou a ser agente diplomático.

Como o francês CONSUL, nesse novo sentido, proveniente do italiano (Bloch e Wartburg), e assim também o alemão KONSUL (Wasserzieher), é provável que o port. CÓNSUL tenha essa origem, cujo documento mais antigo, consoante J.P. Machado, é de 1338. Respeitante ao espanhol, Corominas data CONSUL de 1182, em baixo-latim italiano. Tenha-se presente a importância das relaçōes comerciais italianas na Idade Média.

Entre os romanos a esposa do cônsul era denominada FEMINA CONSULARIS, "mulher do cônsul" (port. CONSULESA, que é também a "funcionária administrativa de um Estado"). Em port. CÔNSUL vem sendo também usado como "funcionária encarregada de um consulado".

É obscura a origem do lat. CONSUL. Os antigos romanos o tinham como pós-verbal de CONSÚlERE, "deliberar, tomar conselho, consultar". "Se, dizem Ernout e Meillet, o sentido de "consultar, pôr em deliberação em uma assembléia" conduz a ver no termo o prevérbio CON- (COM-), o segundo elemento, contudo, não se deixa determinar, por impossibilidade de retraçar, com exatidão, a origem e as funçōes dos magistrados chamados CONSULES, e assim também o primeiro sentido de CONSÚLERE".

Foram aventadas várias hipóteses, que não convencem, mas é possivel tratar-se de empréstimo, todavia indemonstrável. (E. e M.).

PESSOA - do lat. PERSONA recebeu o port. PESSOA por meio do arc. PESSOA. PERSONA, "máscara teatral, etc.", foi acolhido pelos romanos provavelmente do grego PRÓSÓPON, com igual sentido, através do etrusco PHERSU, "máscara teatral".

A forma do etrusco parece que se pode explicar primeiramente como se o grego PRÓSÔPON fosse derivado de um hipotético PROSO (cf. etrusco PUMPU - PUMPUNI, lat. 
POMPONIUS), e, em segundo lugar, foi desfeito o grupo consonantal $\mathrm{PR}$, inexistente na lingua etrusca.

Não está claro como se formou o lat. PERSONA, cuja terminaçāo lembra nomes como LATONA, POMONA, etc. E provável que o verbo PERSONARE, "fazer ressoar, soar muito", aliado à idéia do modo de falar de mascarado haja contribuido para a forma PERSONA. Ademais, o adjetivo PER. SONUS, "ressoante", pode ter favorecido a formação de PERSONA.

PROSÓPON significava tão-somente "olhar; aspecto", composto de PRÓS (cognato do gr. PRÓ), "diante, em frente", e de ÓPS, ÓPSÓS, "olho; vista". Passou a significar "rosto, cara", e, na linguagem teatral, "máscara", e da idéia de "mascarado" deriva a de "papel desempenhado por um ator", e, em seguida, "personagem de drama", e mais tarde "indivíduo, pessoa".

Todavia, segundo L. Deroy, o etrusco PHERSU é o nome próprio de um personagem mascarado, inscrito duas vezes na tumba dos augúrios (Tarquínia). " $E$ ' preciso, diz o mesmo autor, conhecer melhor as crenças e os ritos funerais dos etruscos para poder passar seguramente do nome de um per. sonagem mítico dos infernos para o de um personagem tipico dos jogos e do teatro" (L'EMPRUNT LINGUISTIQUE, p. 34 , nota 5 ).

LUZIR - Este verbo deriva do lat. LUCIRE (em vez de LÜCERE), "iluminar", porém cujo sentido pré-histórico deveria ter sido "brilhar (ou iluminar) abruptamente" (Trom. betti), graças ao "determinativo" da raiz $\mathrm{K}$.

A raiz indo-européia é "LUK ou, melhor, "LEUK, que se verifica, entre outros, nos derivados LUX, LUCERNA, LUNA. LUSTRARE, LUCUBRARE, LUMEN.

Do acus. LUCEM (com a queda do $M$ ), através de "LUZE do port. arc., chegou-se a LUZ. LUCERNA, "lâmpada de queimar óleo", deu o port. LUZERNA, "clarão". LUNA, propriamente "a luminosa". era antes "LOKSNA e "LEUKSNA; veio a ser "lua" (port. LUA). Substituiu, por motivo religioso, o verdadeiro nome do satélite, que era aproximadamente *MENE, do gênero masc., base do lat. MENSIS, "mês lunar" (cp. ingl. MOON, alemão MOND). LUSTRARE, "aclarar, iluminar", parece denominativo de LUSTRUM, "curso do sol", derivado de "LOUKSTROM. LUCUBRARE, "trabalhar à noite (mediante lume)", é origem do port. LUCUBRAR, vocábulo erudito. LUMEN, anteriormente "LOUKSMEN, significa "lume", porem, dizem E. e M., difere de LUX, porque LUMEN designava primeiramente um meio ou recurso de 
iluminar, isto é, em sentido concreto. Promana do port. LUME.

Da mesma raiz proveio o gr. LEUKKós, "branco", mas cujo sentido primitivo era "luzente, brilhante" (cf. o paralelo semântico em BRANCO). Dai o elemento de composição científico em LEUCÓCITO, LEUCEMIA, etc.

A forma mais antiga da citada raiz é "WEL-K-, de que proveio o hipotético "UOLCA, "fogo" > "fogo do vulcão" $>$ "vulcão". Este nome foi divinizado pelos romanos sob a forma VOLCANUS, VULCANUS (de aspecto adjetival), "deus do fogo do vulcão", e dai o nome comum port. VULCÃO. E provável que UOLCA seja de origem etrusca (cf. os gentílicos VOLCA, VOLCHA).

BRANCO - BLANCU, donde o port. BRANCO, é latiniza. ção do germânico BLANK, "brilhante, luzente, lustroso", como um dos resultados do bilingüismo germano-romano verificado entre o 5." e o 8." séc. De BLANCU promanam di. reta ou indiretamente, também, o espanhol BLANCO, italiano BIANCO, francês, provençal e catalão BLANC.

O alemão atual possui o adj. BLANK a valer "lustroso, brilhante, luzido". Coligam-no ao indo-europeu "BELE-G-, "brilhar" (daí o lat. FÚLGERE, o gr. PHLEGO, etc.

O problema, que parece insolúvel, diz respeito à preferència pelo termo germânico, talvez primeiramente referido a objetos próprios dos teutões. $O$ certo é que os estrangeiris. mos exercem fascinio, sobreestimados por qualquer motivo.

O vocábulo que exprime "branco" em lat. é principalmente ALBUS, de que resultou o port. ALVO, o qual, certo, prevaleceu com o mesmo sentido em algumas regiōes de Portugal. Todavia, é uma forma semiculta, em vista da manutenção de AL- (popularmente seria "AUVO e dai *OUVO; cf. FALCE > FAUCE > FOUCE). Documenta J.P. Machado ALVO, como antônimo de NEGRO, neste passo dos DESCO. BRIMENTOS PORTUGUESES, I, supl., p. 363: “. . . que elle podesse poeer por corretor dos mouros e mouras negros e ALUOS..." (ano 1460). Não é, pois, latinismo, como afirma M. Said Ali ("Nomes de Cores" na REV. DE CULTURA, 36 , 1944, p. 7).

O sentido primitivo de "brilhante" permanece ainda em ARMA BRANCA (referente ao brilho do metal). Contudo, a mesma expressāo pode ser baseada no próprio germânico, cuja herança é o alemão BLANKE WAFFE, "arma branca", e assim também o espanhol ARMA BLANCA, o italiano ARMA BIANCA, o francês ARME BLANCHE. Sinônimo do alemão BLANK é WEISS, porém não se diz WEISSE WAFFE. 
Talvez o maior peso na preferència de BLANCUS está o fato de ser ALBUS o branco desprovido de brilho, conforme o testemunino do gramático Sérvio Honorato (séc. $4 .^{\circ}$ ) (v. Ernout e Meillet, e J. André, ÉTUDE SUR LES TERMES DE COULEUR DANS LA LANGUE LATINE, Paris, 1949, p. 26). Consigna $\mathrm{H}$. Brunswick no DIC. DE SINÔNIMOS LATINOS, Porto, 1893, p. 27: "ALBUS designa o branco considerado como a negação de toda a cor, como uma coisa incolor, e só se diz dos objetos naturais". Atualmente ALVO expressa intensidade na brancura. CANDIDUS exprime, sim, o que brilha (cp. CANDERE, "estar incandescente; ser de um branco brilhante"). O port. CÂNDIDO é pura forma erudita; nāo se popularizou.

Na liturgia católica "a cor branca simboliza a glória, a majestade, a alegria, a inocência, a imortalidade, pelo que é empregada nas festas de Nosso Senhor (menos nas da Paixão), de Nossa Senhora, dos Anjos e geralmente nas dos Santos" (Fr. B. Röwer, DIC. LITÚRGICO, s. v.).

Como paralelo semántico, o gr. LEUkós, s. v. LUZIR.

LADAINHA - E forma popular correspondente à erudita LITANIA, do lat. eclesiástico LITANIA (o 1.० I é breve, e longo o 2..$^{\circ}$. Houve também a forma LETANIA (lat. ecles.). O lat. é tirado do gr. LITANEIA, "súplica, prece", baseado em LITE, com o mesmo sentido.

No port. ant. houve LEDAI(N)A (com I nasal) e provavelmente da forma anterior LEDĀIA. Outras formas arcaicas são LEDAINHA, LADEINA. Esta talvez esteja por LA$\operatorname{DEI}(\mathrm{N}) \mathrm{A}$.

LADAINHA é "uma série de invocações que a Igreja faz ao nome de Deus, de Maria Virgem e dos santos". Ela possi. velmente teve origem em Roma, e com procissão solene, por isso era também designaçāo desta, mediante cânticos ( $A$. Blaise).

Houve LITANIA MAIOR, "procissão anual de S. Lourenço, no Vaticano, ou de S. Marcos (ladainha de Todos os Santos)"; LITANIA MINOR, "rogaçōes em 3 dias precedentes à Ascensão" (instituida na Gália, séc. 5.0); LITANIA SEPTENA, composta de 7 coros, no Sábado Santo, junto às fontes batismais; LITANIA SEPTIFORMIS (de Gregório Magno), formado por clérigos, monges, religiosas, homens, mulheres casadas, viúvas, pobres e crianças. Saía de uma para outra igreja. E a origem de LITANIA MAIOR (de $\mathbf{S}$. Marcos) (A. Blaise).

Em virtude de as ladainhas nāo serem breves, passou LADAINHA, na linguagem popular, a "série longa e, por- 
tanto, fastidiosa de palavras; palavras repetidas", donde a frase-feita VIR COM A LADAINHA DE SEMPRE, "repetir as desculpas, as histórias, etc., que sempre se diz" (A. Nascentes).

PÓNEI - "cavalo da Bretanha, pequeno, porém ágil e fino" (Aurélio) - provém do fr. PONEY, o qual, por sua vez, é adaptação do ingl. PONY. Dão como origem deste o lat. PUILANU, "cavalinho", mas esta etimologia não explica a forma inglesa. Na realidade trata-se de um vocábulo de origem céltica, da base "EPO-, "cavalo", aparentado ao gr. HIPPOS. Sua forma próxima é EPONA, deusa dos celtas continentais, cujo totem é o cavalo ou a égua. Aquele termo deve assentar num hipotético "EPO-N-, "égua", da lingua céltica.

EXPLICAR - î forma culta, do lat. EXPLICARE. Este verbo havia inicialmente ideia fisica ou material; é composto de EX, idéia de "exterioridade", e de PLICARE, "trançar, doirar, enroscar", variante de "PLECARE, por sua vez aparentado de PLECTERE, "tecer, enlaçar, entrelaçar, unir, encaracolar, encrespar, frisar".

PLICARE, com o sentido material citado, passou com o prefixo EX, donde EXPLICARE, à idéia de "desdobrar, desenrolar, desembruihar, desembrenhar, desembaraçar", e, em seguida, à idéia imaterial de "clesembaraçar idéias, desenvolver, tornar intelegivel ou claro algo que é obscuro, explicar".

FELINO - E um adjetivo erudito, do lat. FELINUS. O sinônimo FELIDEO é de formaçāo vernảcula, da linguagem cientifica.

FELINO quer dizer "de, relativo ao, ou próprio do gato, ou semelhante a ele", e é empregado também como substantivo, e igualmente FELIDEO.

FELINUS tem por base o subst. FELES ou FELIS, do masc. e do fem.: "gato, gata". Foi também aplicado à fuinha, à doninha, ao furão.

Para Ernout e Meillet não há nenhum cotejo aproximativo com outro ou outros vocábulos; estão inclinados a tê-lo como empréstimo de uma língua desconhecida.

Trombetti, no entretanto, encontrou palavras em várias línguas com as quais ele vê aproximação (DI ALCUNI NOMI DEL CANE E DI ALTRI CARNIVORI, Bolonha, 1914, p. 7): idiomas bantus PITI, PITSI, BITI, PISI, FISI, PHIRI, todos com o sentido de "hiena", porém, no magiame, I-FISI com o de "animal feroz" em geral. O berbere (língua camita) possui 
I-FFIS, "hiena". Enfim ele postula uma forma ${ }^{*}$ PHEL para o proto-indo-europeu, do qual decorre o lat. FELES e o persa ant. PAL-ANG, "tigre, pantera, leopardo".

São cognatos o telugu (idioma dravídico) PILLI, kharia (munda) BILAI, "gato", bahing (tibeto-birmano) BIR-, etc.

LITURGIA - O termo gr. LEITOURGIA, de acordo com sua composição, quer dizer "serviço, trabalho (ERGON) pú. blico (LEfTOS)".

Entre os antigos helenos, pagãos, era trabalho público a que a autoridade obrigava os cidadãos em caso de necessidade ((guerra, calamidade, etc.), mas incluiam-se na designação também os serviços públicos obrigatórios da prática religiosa. O Cristianismo veio a empregar LEITOURGfA para significar "o cuidado para com os pobres" ( 2 Cor 9,12), "esmolas ao Apóstolo" (Flp 4,16), e "ministério público religioso" (Lc 1,23; At 13,2; Hbr 8,3,6, etc.), e "o sacrificio eucarístico" ou "missa".

Foi latinizado sob a forma LITÚRGIA, mas foi conservada a tonicidade grega no port. LITURGIA.

$\mathrm{Na}$ Igreja latina o sentido ampliou-se; é qualquer função sagrada, executada pela hierarquia eclesiástica". (D. Antőnio Coelho, CURSO DE LITURGIA LAT.).

FEIJAO - Segundo A. Carnoy ("Substrat et Adstrat en Grèce" em ORBIS, VIII, 2, 1959, p. 427), uma fava semelhante a feijāo tem origem oriental (da China?), que os gregos vieram a chamar PHASELLOS e os romanos BASELUS. Tem como fonte comum o indo-europeu "BHAKOS, "fava" (donde o gr. PHAKOS, "lentilha"), por sua vez do traco-pelásgico. O -K- nesse termo indo-europeu é palatal, donde a forma assibilada *BAS-. O BH passou a $B$ em regiōes helênicas, e, em outras, também helênicas, veio a ser PH, donde PHASELLOS e daí o lat. PHASELUS, FASELUS, "feijāo".

Quanto ao port. FEIJÃO, nāo esctá bem clara a sua etimologia. S. da Silva Neto dá um lat. 'FASEONE como fonte. "FASIONE, sim, explica FEIJĀO. Diz-se que houve mudança de "sufixo".

No lat. vlg. ao lado de FASEOLUS houve FASSEOLUS e FASSIOLUS.

O galego possui FEIXOO, anteriormente FEIJOO (donde o nome próprio FEIJÓ), assentado em FASSIOLU. A varian. te FEIXON foi influenciada pela forma portuguesa.

FIL(O)- - O gr. PHílOS, "amigo", é elemento de compostos helênicos, p. ex. PHILOSOPHía, "amor à ciência", PHILTRON, "meio de fazer-se amar; sedução; filtro", e usado 
na linguagem cientifica internacional, p. ex., fr. PHILATÉLIE, donde o port. FILATELIA, "prazer em colecionar e estudar os selos postais". - Conforme A. Trombetti, o gr. PHfLOS, "amigo", com muita probabilidade deveria, primitivamente, haver o significado "(o) outro" e dai "companheiro, amigo", e aparentado ao sânscrito A-PARA-, "outro, posterior, segundo".

Há paralelos semânticos: sânscr. ARYA-, "companheiro", da base indo-eur. "ALIO., "outro"; gr. HETAIROS, "companheiro, amigo", cognato de HÉTEROS, "(o) outro"; gueez (camita) KALE, "outro, segundo, sócio"; bégia (camita) RAU, "outro, segundo, companheiro"; caingangue (América do Sul) ARENGRE, "dois, segundo, amigo".

RUBEOLA - É termo erudito (segundo J.P. Machado, é do esp. RUBÉOLA), nome de uma doença epidêmica, febril, caracterizada por erupçōes avermelhadas no corpo. Sua origem é o lat. RUBEOLA, "um tanto vermelho, avermelhado", talvez abreviamento de RUBEOLA DOLENTIA, "doença avermelhada", ou de RUBEOLA INFIRMITAS, "enfermidade avermelhada".

PRUDENTE - O lat. PRUDENS (genit. PRUDENTIS) é o resultado da redução de "PROUIDENS, "previdente", de PROUIDERE, literalmente "ver (UIDERE) com antecedência (PRO)", "prever". Mas PRUDENS veio a ser "acautelado, sagaz, que enxerga longe", donde o port. PRUDENTE, vocábulo culto.

De PRUDENS formou-se o subst. PRUDENTIA, "previdência, previsāo, sabedoria, inteligência" e daí "circunspecção", (port. PRUDENCIA, erudito).

No lat. de autores cristãos PRUDENTIA chegou a ser título honorífico (PRUDENTIA TUA em S. Jerônimo, EPIS. TULAE, 74,6, e, em S. Agostinho, EPISTULAE, 571; 258,5).

De PROUIDERE criou-se o subst. PROUIDENTIA, "presciência, suprema sabedoria", de que os romanos forjaram uma deusa, talvez inspirados na divindade helênica PRONOIA, do subst. comum PRÓNOIA, "previsão, presciência; oráculo", mediante os elementos PRO', "antes", e NOÉO, "ver, meditar, ser prudente".

PROUIDENTIA entrou na linguagem religiosa cristã (PROVIDENCIA, em port., termo culto), com sentido diferente. Enquanto entre os pagãos tinha-se a divindade como "presciente, que vê o futuro", a PROUIDENTIA cristã é "aplicada a Deus como conservador e governador do universo para o fim que ele propôs". 
São formas populares PROVENCIA, PROVINCIA, desaparecidas para evitar colisão com PROVINCIA do lat. PROUINCIA.

ATACADO - Na linguagem comercial ATACADO, subst., é o "comércio de mercadorias em certa quantidade". POR ATACADO vem a ser "em certa quantidade".

No port. arc. dizia-se EM GROSSO, documentado em 1269: “. . saluo que o vizio da villa uenda mel ou azeyte de ssa collecta e de ssa lauradea a EN GROS hu quiser" (apud J.P. Machado), isto é, "salvo que o vizinho da vila venda mel ou azeite de sua colheita e de sua lavoura a em grosso onde quiser".

No verbete MIÚDO do Dic. de Morais (1813) o antônimo de EM GROSSO é POR MIÚDO ou EM RETALHO, e como sinônimo de EM GROSSO é EM PARTIDA ou EM JUNTO.

A RETALHO está documentado, conforme JPM, em 1181: "Si uoluerit uendat et non retalu (RETALIUM) nisi in propria feria', i. é. "se quiser, venda e não (a) retalho, a não ser na própria feira".

ATACADO é, originariamente, participio de ATACAR, a querer dizer "carregar muito algo, encher demasiado", decorrendo daí o sentido de "em quantidade".

De VAREJAR, "medir com vara", tirou-se VAREJO, "ven. da por miudo", antônimo de ATACADO. VARA, "medida antiga, consistia em um metro e dez centímetros".

ALFACE - ALFACE, nome de uma planta hortense (Lactuca sativa, Lin.) de muitas variedades, é do árabe, caso genitivo, AL HACI), "a alface" ou, melhor, "de alface". A forma arc. ALFAÇA, popular em Portugal e no Brasil, pertence ao acusativo (documentada em 1279, segundo JPM). A fforma ALFACIA, também popular, resulta da confusão de ALFACE com ALFAÇA. - A planta é originária da india, e os romanos lhe chamaram (HERBA) LACTUCA, "(erva) de leite", em vista de se poder extrair um suco leitoso. Plínio lhe dá o nome pleonástico LACTUCA LACTENS, "leituga leitosa". De LACTUCA se tem o port. LEITUGA (Crepis barbata, Lin.). A alface ou leituga selvática (Lactuca scariola, Lin.) deu origem, conforme se crê, à variedade hortense.

VICIO - forma erudita, do lat. UITIUM, "vicio, defeito, falta, falha, má qualidade, imperfeição, inconveniente" (Saraiva). Certamente se deve ao lat. ecles. a introdução, aportuguesada, da forma VfCIO, "tendência habitual para o mal". Popularmente deu VEZO, "costume, hábito (geralmente mau)". 
UITIM nāo tem origem indo-européia, mas, consoante L. Deroy, a sua base é etrusca *VIT- ou -*VET-. O significado primitivo de UITIUM era "sinal de augúrio em geral", mas praticamente "sinal augural desfavorável" e "impedimento ritual". Acha-se documentado em Catāo ID MIHI NON UITIUM FACIT, "isso não me é de mau agouro", e em Cícero UITIO NAUIGARE, "navegar com presságio desfavorável".

Pö extensāo, UITIUM passou a "defeito, falha, tara, vicio". O adjetivo daí decorrente - UITIOSUS - significava outrora "defeituoso, mau, corrompido" (port. VICIOSO), e o verbo UITIARE (port. VICIAR) era "realizar algo sob signo desfavorável; pôr sob a ação de uma interdição ritual" e em seguida "causar defeito, alterar, corromper, deteriorar, ultrajar, desonrar".

Da mesma base etrusca promana UITARE, "verificar um signo augural", cionde principalmente "examinar se não há signo augural desfavorável"; "estar alerta contra qualquer sinal adverso; impedimento; acidente, etc." e dai o sentido de "evitar, fugir de, preservar-se; temer", etc.

Mais expressivo é EUITARE, com o prefixo $E(X)$-, e dai o culto EVITAR, em port.

Outro verbo latino dotado de UITIUM, assim reconhecido por E. e M., é UITUPERARE (port. VITUPERAR, culto), "opor um signo desfavorável, um interdito", e, por extensão, "censurar, criticar, repreender". Esses autores reconhecem que UITUPERARE pertencia originariamente à linguagem augural.

SUFRAGIO - O verbo lat. SUFFRAGARI (SUB FRAGARI) tem o sentido de "dar voto, votar a favor de; ser a favor de, apoiar, patrocinar", e dele se fez o subst. SUFFRAGIUM, "sufrágio, voto; aprovação; favor; estima". Mas, na realidade, a base de SUFFRAGARI é um subst. que devera ter existido no lat. — *FRAGUM - sinônimo de FRAGMEN, FRAGMENTUM. "FRAGUM seria um "fragmento", uma tabuinha com que, nas assembléias do povo, na votação do senado romano, os cidadāos e os senadores exprimiam os seus sufrágios.

Esses objetos, que podiam ser de metal ou de marfim, eram encerados, e neles os eleitores escreviam, ou mandavam escrever, o nome de seu canclidato, e os colocavam numa CISTA, "cesta, urna". Serviam também como bilhete de entrada em teatro, de senha ou de contra-senha, etc.

"FRAGUM pertenceria, então, como FRAGMEN, "peđaço, fração", à familia de FRÁNGERE, "espedaçar, quebrar, fragmentar", e desapareceu, talvez, por colisão com FRAGUM, nome de uma planta, com FRAGUS, "curva da perna; bolbi- 
lho dos musgos", com FRAGA, "morango". Seu substituto foi TESSERA.

SUFFRAGIUM foi empregado pelos escritores cristāos da antiguidade com os sentidos de "socorro, auxilio, apoio; intercessāo; orações; aprovação (necessária para ordenaçāo episcopal)".

$O$ vocábulo entrou no port. por via eclesiástica, donde a forma SUFRÁGIO, e assim também o verbo SUFRAGAR < SUFFRAGARI.

SUFRÁGIO, na linguagem religiosa, é usado quase somente como "toda obra feita com a intenção de prestar alívio às almas que sofrem no Purgatório (Pe. J. Lourenço, DIC. DA DOUTRINA CATÓLICA, s.v.; Fr. Röwer, OFM, DIC. LITÚRGICO, s. v.).

Da linguagem profana é que veio o emprego jurídico de SUFRÁGIO, SUFRAGAR. Não tem fundamento o étimo SUB, "embaixo", e FRAGOR, "fragor, ruido forte", isto é, "aclamação", embora, antes do uso de tabuinhas, a votação dos romanos fosse de viva voz, até o ano 139 a.C.

PRETO - Tem sido muito discutida a etimologia de PRETO, "negro"; "que tem a mais sombria de todas as cores" (Aurélio). A hipótese mais aceitável é a de J. Inês Louro (BOLETIM DE FILOLOGIA, IX, p. 79-84). Trata-Se do particípio "PRETTU, em vez de PRESSUS (de PREMERE, "comprimir", etc.), que, entre outros sentidos, possuia o de "sombrio, escuro". O mesmo étimo serve para o espanhol PRIETO.

Fora da Peninsula Ibérica foi o tradicional NIGRU (com I breve) que dominou: italiano NERO, provençal e catalão NEGRO, romeno NEGRU, francês NOIR, etc. Também na Ibéria aquele veio a existir: port. e esp. NEGRO.

Deve ter sido o eufemismo a causa do aparecimento de "PRETTU, visto como NIGER, NIGRA, NIGRUM além de ser aplicado à pessoa de cor, designa "malfazejo, perverso, malvado; hipócrita; funesto, fatal". Nāo obsta o fato de ser o eufemismo delimitado à Ibéria, pois um fenômeno lingüístico pode vigorar só numa área e não em outras, mesmo contiguas, embora tenha a mesma causa. Em outras áreas deve haver outros recursos.

Verifica-se, no port., ainda hoje a relativa suavidade no emprego de PRETO, em vez de NEGRO, em referência a pessoa. Cp. ainda VIDA NEGRA, HORA NEGRA, A NEGRA INGRATIDĀO, e o provérbio NEGRA E A MERCE QUE TARDA E MAL AGRADECIDA.

A. Nascentes no DIC. DE SINŌNIMOS: "PRETO repre. senta o acidente de cor em toda a sua realidade e nada tem de ofensivo. NEGRO tem caráter ofensivo". 
SACRÁRIO - SACRÁRIO é o "tabernáculo onde, em cibório ou pixide, são guardadas as hóstias consagradas". Trata.se de vocábulo culto, do lat. SACRARIUM, que, no paganismo, era "lugar onde se conservavam as SACRA", $i$. é, as coisas sagradas do culto: estátuas dos deuses, vasos, alfaias, utensilios para os sacrifícios (Virgilio, Ulpiano). Significava ainda "templo, santuário" (Marcial), "capela, oratório", que podia estar no palácio imperial (Cícero), "aposento do imperador" (Ausônio), "cerimônia religiosa, culto" (Propércio, Prudêncio) e "lugar secreto e oculto" (Sêneca).

Designou SACRARIUM também o templo de Jerusalém, e entre escritores cristãos apareceram tais expressões: RÉGENERATIONES SACRARIUM, "sacrário da regeneração", i. é, a fonte do batistério, e também igreja; SACRARIUM UIRGINITATIS, "sacrário da virgindade", i. é, a continência. No pl. SACRARIA: "religiāo; ritos" e "sacristia (guarda de objetos do culto)".

TREMER - Da onomatopéia "TETE (redobro expressivo), "tremer de frio", donde também "tremer de medo", criou o proto-indo-eur. "TETE-M- (com M, "determinativo" da raiz), e, por dissimilação, "TERE-M-, donde o lat. TREMERE, "tremer" (Cícero), "palpitar" (Virgílio), "temer" (Cicero, Tito Livio), cf. TRÉMERE ANIMO, "tremer de medo", e os adj.. TREMULUS, "que treme, vacilante", TREPIDUS (com o "determinativo" P), "trepidante, agitado", de que se fez TREPIDARE (port. TREPIDAR), e acrescente-se INTREPIDUS, "não trepidante, intrépido".

Com exceção do port. TREMER, que veio popularmente de TREMERE, os demais cognatos são eruditos no port.: TREMULO, TREPIDO, TREPIDAR, INTREPIDO.

Da mesma raiz é o gr. TRÉM-Ô, "tremer de medo" e "temer", e com variação vocálica o gr. TAR-TAR-IZó, "tremer de frio", c o sânscr. TARA-LA-, "tremente, instável".

Ao passo que o lat. 'TRÉMERE, afirmam E. e M., significa simplesmente "tremer", TREPIDUS, TREPIDARE designam antes uma agitação inquieta e febril".

Parentesco remoto: Ár. TAR-TARA, "abalar violentamente", assírio TARÁRU, "tremer, estremecer", cafre-tetense TETE-ME-RA, “tremer".

Para Felice Bruni (L'ORIGINE DEL LINGUAGGIO, Roma, 1958, p. 46-47), ao lado da onomatopéia *TETE há "TER, ambas com o mesmo valor: "O arrepio por frio, por medo, por febre, além do tremor dos membros, é acompanhado do batimento dos lábios e dos dentes", dando lugar, entre outras, às manifestações expressivas T-T, T-R,D-R (dialeto toscano DARDELLARE, "tremer de frio"). 
A onomatopéia *TITI (redobro de "TI) significa tão-só "temer" no indo-eur. pelo lat. TIMERE, "ter medo" (port. TEMER), derivado de "TI-M-, aparentado pré-historicamente do bantu TI-TI-MA, "ter medo" (contudo, cafre-tetense TETE, "medo").

ÓSCULO - O lat. OS, "boca", era anteriormente *AUS, que se documenta com AUSCULUM, depois OSCULUM, "boquinha" e daí "beijo" (port. ÓSCULO, erudito). Paralelo semântico: port. do Brasil BOQUINHA, "beijo". É cognato daquele OSCITARE, "abrir a boca, bocejar". Todos têm base em $\approx$ AU-S-C, $*$ O-S-C-, diminutivo.

Ainda como diminutivo de OS é OSCILLUM, "boquinha", talvez mais expressivo que OSCULUM, pela presença da vogal I. OSCILLUM tem ainda, por analogia, o esntido de "pequena cavidade no centro de leguminosas", donde sai o germe. Em vista dessa cavidade, aplicou-se, por certa semelhança, o nome a uma figura ou máscara de barro, oferecida, como vitima expiatória, a Saturno e a Baco, a qual, suspensa em árvores (pinheiros, vinhedos, etc), era agitada pelo vento. Deste fato se criou OSCILARE, "balançar, agitar (como essas máscaras)", de que resultou o port. e o esp. OSCILAR, o fr. OSCILLER, o ital. OSCILIARE.

O subst. criado do lat. OSCILLARE veio a ser o homófono OSCILLUM, cujo sentido é "redouça, balouço", que não vingou no port.

PARPALHAÇA - Na 4." ed. do DIC. de Figueiredo consta, como registrados pela primeira vez, PARPALHAÇA, PARPALHAZ, PARPALHO' e PARPALHÓS, todos fem., e signifi. cam "codorniz" (Coturnix communis). São regionalismos beirōes, com exceção dos dois primeiros, transmontanos.

Somente após PARPALHO' Figueiredo the dá o étimo, i. é, onomatopéia.

O Dic. Aulete averba como masculinos PARPALHAZ, PARPALHO', PARPALHÓS.

A codorniz emite gritos, e por eles é que se criou o lat. COÁCULA, COACCULA, QUÁCCOLA, donde manam o fr. CAILLE, o ital. QUAGLIA, etc. Há em lat. ainda QUÁRQUARA, que figura somente em glosas. Para E. e M. é, sem dúvida, vocábulo estrangeiro, acrescentando ser de formaçāo expressiva em redobro. De fato, há duplicação não só em QUARQUARA, mas também nas demais formas latinas. Dizem os romanos que a ave foi assim chamada em vista de sua manifestação vocal.

Os regionalismos port. têm base em redobro, i. é, " PAR ou "PAR-PAL, e, embora seja onomatopéia (a reprodu- 
ção nunca é perfeita), pode, todavia, ser de origem basca PARPARA, "codorniz". De formação símile é o letão PALPALA, o prussiano PENPALO, o russo PEREPEL (no diminut. PELEPELKA), todos como "codorniz".

CLERO - Termo erudito, CLERO é do lat. CLERUS, e este do gr. KLEROS, cuja forma anterior é o dórico KLAROS.

Primitivamente KLEROI (pl.) era a denominação de pe. drinhas ou pedacinhos de madeira que, postos dentro de um capacete, e, mais tarde, dentro de um recipiente, serviam, após agitá-los, para sortear a quem caberia um objeto, um cargo, etc.

É o termo cognato de KALEÓ, "chamar", pelo fato do tilintar as pedrinhas dentro do recipiente.

KLEROS passou a ser "sorteio de algo" e "quinhão que, mediante sorteio, cabe a alguém, especialmente numa herança" e mesmo "herança". O gr. tem ainda o composto KLERO. NOMIA, "participaçāo em uma herança".

Na Biblia, Deus se declarou "herança" dos sacerdotes e levitas: Estes e aqueles "não terão herança entre seus irmãos: o Senhor será a sua herança..." (Dt 18,2).

Assim, a latinização CLERUS passou a designar o "conjunto dos levitas do Novo Testamento, i. é, os consagrados a Deus, sacerdotes, seculares e regulares".

Alguns derivados de CLERUS: CLERICUS, que se substantivou no port. CLÉRIGO (forma semiculta), "membro do clero"; CLERICIA > port. CLEREZIA, o mesmo que CLERO (outra forma: CLERIZIA, arc.), CLERICALIS, adj., port. CLERICAL, CLERICATUS, port. CLERICATO (erudito).

PREMIO - Do lat. PRAEMIUM > PREMIO, "recompen. sa material ou moral; paga; gratificação; galardão", em vista de qualquer obra executada ou em competição, jogo ou concurso. Mas o sentido primevo era "parte dos despojos, da presa de guerra, tomada ao inimigo, e ofertada à divindade que deu a vitória, ou ao general vencedor". Teve, pois, o termo nascimento na linguagem militar dos romanos, certo como abreviamento da locução PRAEMIA PUGNAE, "despojos do combate".

PRAEMIUM é composto de PRAE com idéia de anterioridade, e de "EMIOM, "EMIUM, "ação de tomar, apanhar, prender".

E plausivel que a ídéia de anterioridade seja relacionada com a preocupação com a tomada dos despojos, das riquezas dos vencidos, um dos fins da guerra de então. Da linguagem 
militar passou para a comum: "proveito, recompensa legitima".

Dizem E. e M. que a paronímia com PRETIUM, "preço, valor, recompensa, mérito", influiu no sentido de PRAE. MIUM, o qual, na origem, era sinônimo de PRAEDA, "preda, despojos de guerra".

CASTO - O subst. lat. CASTUS, termo religioso pagão, queria dizer "cerimônia religiosa, para a qual se preparava com abstinência; rito; prescrição religiosa" (Saraiva), e, como adjetivo, CASTUS valia o mesmo "que se regulamenta religiosamente; relativo a cerimônia religiosa" (aplicava-se tanto a pessoas quanto a coisas). E o seu correspondente o sânscr. ÇISTAH, "instruido, educado".

CASTUS confundiu-se com o homófono CASTUS, coradical de CARERE, "ter falta de; estar privado de; estar isento de", e, por isso, o adj. CASTUS veio a ter o sentido de "isento de; puro; isento de falha, especialmente de impureza; virtuoso". (Port. CASTO).

O adj. criado para se relacionar com CARERE foi CASSUS, "vazio; vácuo; privado de; desprovido de; falto de; vão, inuitil".

Alicerçado em CASTUS, "isento de, puro, etc.", formouse, entre outros substantivos, CASTITAS, CASTITATIS, "castidade", que, entre os romanos, era "pu reza de costumes; honestidade (mormente das mulheres)" (Cicero, Tácito). Em Aulo Gélio e Macróbio: "integridade; santidade", em Vitrú. vio: "probidade".

Para a Igreja Catćlica, CASTITAS veio a ser "virtude da pureza moral e espiritual" (Port. CASTIDADE).

De CASTUS, "que se regulamenta religiosamente", deriva-se CASTIGARE, cujo significado primitivo, infelizmente, não se acha documentado, e que devia ser "instruir (para cerimônias religiosas)", e daí, certamente por falhas, "repreender, corrigir", e, por fim, "castigar". Em consequiência nāo tem relação com CASTUS, "isento de, puro, etc."

Do antōnimo INCASTUS, "não casto", adj. que não se acha documentado, resultou INCESTUS. Tal se explica apofonicamente, i. é, a vogal I influiu na vogal $A$, passando a $E$.

INCESTUS serviu de base para INCESTUM, "impureza, mancha; adultério; prostituição". O Cristianismo aproveitou os termos latinos para aplicar a relaçōes sexuais ilícitas entre parentes.

O port. INCESTO (lat. INCESTUS), INCESTUOSO (lat. INCESTUOSUS) e INCESTAR (lat. INCESTARE) são todos termos cultos. 
LATIM - De acordo com o lat. UINU de que resultou o port. VINHO, assim também do lat. LATINU promana 0 port. LADINHO, que, no port. arc., como substantivo, era a "lingua latina", e, como adj., "relativo ao latim; latino; românico": LINGUAGEM LADINHA PORTUGUES. Com este mesmo sentido é a forma LADINO. Diz J.P. Machado que o significado atual deste, i. é, "manhoso, astuto" foi precedido pelo de "culto, civilizado". Quem sabia latim, era considerado pessoa culta.

A forma LATINO é erudita. Consoante J.I. Louro ("Nótulas Etimológicas" em BOLETIM DE FILOLOGIA, IX, Lisboa, 1948, p. 96.97) o termo LATIM é importação do francês ou do provençal, e LADINO é do espanhol ou especificamente do leonês, caso não seja forma semiculta ou conservada pelos moçárabes. O legítimo port. é, portanto, LADINHO. $O$ adj. LATINUS é um derivado de LATIUM, "Lácio", inicialmente nome de um distrito à margem esquerda do Tibre Provavelmente queira dizer "Larga (planície)", e aparentado ao umbro TLATIE, genitivo sing. (Brugmann).

GUAI! - A interjeição GUAI!, que se acha no port. arc., parece a mesma do ital. GUAI! De fato é a mesma por coincidência fortuita; uma não passou para outra língua. A origem de ambas é a forma UAI!, a qual ainda subsiste no Brasil. Exprime surpresa ou espanto, mas no ital. dor, ameaça, etc.

Do port. arc. GUAI se fez GUAIAR, "lamentar-se, queixarse; soltar guais; cantar em tom de lamentar", e do verbo o subst. GUAIA, também arc., a significar "lamento, choro".

De AI!, que normalmente designa dor, criou-se o subst. AI, "grito de dor", e daquele ou deste veio AIAR, "dar ais, soltar gritos de dor; gemer". A locuçāo NUM AI significa "em um instante", como num repente se profere a interjeição AI!

Da esquisita interjeição "UAIU, não documentada, passou-se a GUAIU', "alarido".

E. Schwentner admite que a interjeição "WAYO-, "ai!", do proto-indo-europeu explica as inter jeições similes nas línguas daí decorrentes: lat. UAI!, representado mais tarde UAE! ou VAE!; sânscr. VAY, AVAY; gótico e letão WAI; armênio VAY; galês GWAE; etc. É neoformação o grego OUAI', do Novo Testamento.

Segundo o mesmo A., da interjeição germânica *WAI provieram o port., o esp. e o ital. GUAI, o francês ant. WAI, GUAI, fr. atual OUAIS, romeno VAI, etc. (DIE PRIMÄREN INTERJEKTIONEN IN DEN INDOGERMANISCHEN SPRACHEN, Haidelbergue, 1924, p. 24-25). 
O fr. OUAIS, pronunciado UE', não passou ao port. do Brasil UE', UE, interj. de espanto. Há coincidência fortuita.

ARTE - Conforme E. e M., o lat. ARS, ARTIS (donde o port. ARTE) designa frequientemente habilidade adquirida pelo estudo ou pela prática, um conhecimento técnico e daí "talento, arte" (sentido abstrato e concreto), oposto a NATURA, a INGENIUM, a SCIENTIA. Pode tomar um matiz pejorativo: "artificio, astúcia".

Do sentido de "talento, arte", chega-se a "profissão" (donde ARTIFEX, "artesāo, artífice", ARTIFICIUM, etc.) e também a "trabalho, obra", e, portanto, serve para traduzi: o gr. TÉCHNE. E a par de "profissão" surgiu o significado de "conjunto de preceitos relativos ao exercicio de uma arte".

A ARS prendem-se os adj. INERS, INERTIS, "que não sabe fazer coisa alguma, inábil" e daí "inativo" (port. INERTE), e o subst. INERTIA (port. INERCIA), assim como SOLERS, "hábil, destro, ágil" e em seguida "astuto, manhoso, velhaco" (port. SOLERTE), SOLLERTIA (port. SOLERCIA). O primeiro componente é o lat. SOLLUS, "inteiro".

ARS inicialmente queria dizer tão-só "trabalho", cognato que é do verbo ARARE, cujo senticio pré-histórico era "trabalhar", especializando-se logo para "trabalhar a terra, cultivá-la" (port. ARAR).

A mesma raiz indo-européia, que é *ARA-, aparece sob a forma "DARA- no gr.: DRÁÔ, "ser ativo; fazer", DRĀMA, "ação" (port. DRAMA).

De ARTE com o sentido de "astúcia" fez-se o derivado ARTICE, e a pessoa é ARTEIRO, -A.

Do lat. ARS MAGICA, "arte mágica" deriva o fr. arc. ARTIMAGE, "exercicios ginásticos e acrobáticos".

O port. ARTIMANHA, "astúcia, ardil", não parece vir da locução latina, como admite o Pe. A. Magne, mas de ARTE E MANHA, como sinônimos. Para JPM deriva-se do lat. ARTE MAGNA.

CAVALO - O lat. CABALluS (port. CAVALO) sobrepujou EQUUS, que teria o resultado *EGUO, como do fem. EQUA resultou EGUA, que permaneceu.

Teria sido motivada pela plebe urbana de Roma a vitória de CABALLUS, "cavalo para tração, transporte; sendeiro", não só por ser vocábulo mais encorpado, e, portanto, mais expressivo, porém principalmente pelo emprego humorístico ou irônico ao cavalo (EQUUS) de gente nobre.

Segundo G. Rohlfs, o termo proviria de uma língua balcânica (ilírico?) ou da Ásia Menor, através do gr. KABÁLLES 
(atestado em Esíquio, 6. séc. a.C.). Aparentado é o eslavo KOBYLA, "égua".

O documento latino mais antigo de CABALLUS é de Lu. cílio (2." séc. a. C.).

Na Peninsula Ibérica o testemunho mais velho acha-se numa inscrição de Augusta Emérita (Mérida), provavelmente do 1." séc. d. C., numa lista de animais (Rohlfs).

Ao lado de CABALLUS possuía o lat. estes cognatos: CABO, CABONIS, "cavalo castrado", e CABUS, CABONUS, CABONI, cuja terminação (-ONIS, -ONUS) parece pejorativa.

Em vista de os gauleses teres sido notáveis fabricantes de carros (CARRUS, CARPENTUM, etc.) foi proposta para CABALLUS origem céltica.

Em uma língua caucásica, o kürino, o "cavalo velho" é denominado JABU, que poderia ter por ascendente *KABU, e $\because \mathrm{KAB}$ - seria talvez a raiz de CABO, KOBYLA, CABALLUS. O alongamento de -L-, isto é, -LL- teria sido para expressividade.

GUERRILHA - i a "luta de pessoas armadas mais ou menos irregularmente, que se opōem a um governo, lançando mão principalmente de escaramuças e emboscadas, e aproveitando todos os recursos possiveis". O termo é de procedência esp. GUERRILLA, por sua vez dim. de GUERRA.

Embora GUERRILLA já se documente em 1535 (Corominas), o seu emprego máximo foi a começar das lutas espanholas contra o dominio de Napoleão, culminando com a independência (1814).

De GUERRILIA o espanhol fez GUERRILLERO, que passou ao port. GUERRILHEIRO.

Segundo JPM, GUERRILHA, em Portugal, tem documentação de 1836, quando se publicou o periódico OS GUERRILHAS, como sinônimo de GUERRILHEIROS.

INSTRUMENTALISMO - Conforme define A. Cuvillier, é "a forma de pragmatismo que afirma o caráter instrumental da verdade, isto é, que esta é simples instrumento para a. ação e para o enriquecimento da experiência ulterior". (PEQUENO VOCABULARIO DA LINGUA FILOSOFICA, s. v.).

Como o ing. TOOL, "instrumento", traduz o lat. INSTRUMENTUM, o autor de sua doutrina, o filósofo norte-america. no John Dewey (1859-1952) criou INSTRUMENTALISM, ou foi por outros aplicado à sua filosofia.

Do ing. o termo passou ao fr. INSTRUMENTALISME e a outras linguas. 
BATIZAR - O lat. ecles. BAPTIZARE é adaptação do gr. BAPTIZEIN, "submergir, mergulhar; lavar; tirar água", formado na base de BÁPTEIN, "submergir, imergir, mergulhar, embeber, molhar".

Aquele verbo grego foi empregado no Cristianismo com novo sentido, i. é, "imergir alguem para lavar o pecado original, ou os pecados atuais; administrar o sacramento do batismo", e assim no latim.

Ao lado de BAPTIZARE usou-se, entre escritores cristãos, de sinônimos, como recurso estilistico: LAUARE, "lavar", TINGERE, "molhar, banhar", INTINGERE, "embeber, molhar", ABLÚERE, "banhar, lavar, limpar”, MERGERE, "mergulhar".

S. Agostinho empregou PERFỨNDERE como "batizar", não por imersāo, porém efundindo.

O port. BATIZAR (outrora BAPTIZAR) è forma erudi. ta, graças à influência do latim eclesiástico, mas popularizouse sob as formas BOUTIZAR e BOUTIÇAR. Sob a forma BAUTIZAR, arc., é ainda popular em Portugal e no Brasil.

O "ato de batizar" BATISMO (outrora BAPTISMO) é também de origem culta; ficou popular em BAUTISMO, BOUTISMO e BAUPTISMO (cruzamento de BAUTISMO com BAPTISMO). o lat. BAPTISMUS ou BAPTISMUM, por sua vez do gr. BAPTISMÓS, "imersão; abluçāo" e "batismo". É criação do Novo Testamento a forma gr. BÁPTISMA, que foi introduzida no lat. ecles. Usaram-se como sinônimos LAUCRUM, "banho", popular, e TINCTIO, INTINCTIO da linguagem literária.

ESTRADA - Dentre os vocábulos que exprimem "caminho, estrada" (ITER, UIA, etc.), o mais novo é STRATA (donde o port. ESTRADA). Ele surgiu quando os romanos trataram de calçar os caminhos mais importantes. Assim construíram: "Colocava-se primeiro uma camada de cascalho" e sobre ela "colocava-se uma segunda composta de pe. dras brutas que eram cimentadas com cal".

STRATA é abreviação de STRATA UIA, i. é, caminho coberto, calçado, a que se estendeu uma camada de qualquer material. E cognato de STERNERE, participio STRATUM; significa "estender por cima, pôr em cima; cobrir de", e, em consequiência, os sentidos de "empedrar; abrir um caminho; STERNERE UIAS", "calçar estradas".

"As estradas dos romanos não tinham mais do que 15 pés (pouco mais de $4,42 \mathrm{~m}$ ) com um cais dos dois lados (CREPIDINES)", e, "abandonadas a si mesmas, todavia têm podido durar séculos inteiros, pois que, depois de 2.000 anos, delas se encontram ainda vestigios" (Fernandes de Carvalho). 
A propóstito de STRATA diz Meyer-Luebke: "A palavra ciifundiu-se por toda a România, com exceção do romeno, e designou, desde o inicio, a estrada construida em oposição a UIA" (que é caminho não calçado).

"As estradas, continua Fernandes de Carvalho, não eram feitas pelo Estado, mas pelos ricos particulares que obedeciam a um sentimento de patriotismo ou procuravam adquirar por esse meio o favor do povo".

Entre as mais antigas salientam-se a VIA APIA (UIA APPIA), construída pelo censor Cláudio Ceco Apio, em 311 a. C. Partia da porta Capena, em Roma, e através dos charcos Pontinos, chegava a Cápua, e depois prolongada até Brindes e Taranto. A VIA FLAMINIA, que unia Roma a Rimini, foi feita pelo censor e cônsul Gaio Flamínio em 220 a. C. A VIA EMILIA, continuação da anterior, em 187 a.C., teve como construtor o cônsul Marcos Emílio Lépido (Rímini-PlacênciaMilão-Como).

Tais estradas (STRATAE) mantiveram, todavia, o nome antigo de vias (UIAE). Os italianos as denominam STRADE CONSOLARI e tambem VIE CONSOLARI, porque construidas por cônsules.

Em tempos posteriores apareceu a designação STRATA REGALIS, donde o port. ESTRADA REAL, espanhol CAMINO REAL, por ter sido construída a expensas de um rei, e ampla, em oposição a ANGUSTA in ANGUSTISSIMA SEMITA, "senda estreita ou estreitissima". ESTRADA REAL, hoje, quer dizer a principal de uma região.

PIPOCA - PIPOCA, "variedade de milho", é nome de origem tupi. Fazem-no composto de PI-, abreviamento de PIRE", "pele", e da onomatopéia "POK, do estalo que faz o milho ao calor do fogo, e, portanto, interpretado como "pele ou película que espoca". Melhor é ter o elemento PI- como parte integrante de onomatopéia, i. é, o vocábulo é onomatópico.

De PIPOCA derivam-se PIPOCAR, PIPOQUEAR, ESPIPOCAR, ESPOCAR a POPOCAR. Deste último se fez, com dissimilação vocálica, PAPOCAR. POPOCAR, por sua vez, é resultada da assimilação vocálica de PIPOCAR.

A denominação inglesa é parcialmente onomatopaica POP CORN - "milho espocante (POP)".

MINISTRO - Da base latina MINUS, "pequeno; menos": formou-se MINISTER (genit. MINISTRI), segundo o modelo MAGISTER, fundado em MAGIS com a noção de "grande".

MINISTER significava primitivamente "servo, ajudante, escravo", e tambem com certo enobrecimento semântico: 
MINISTRI LEGUM, "os protetores das leis" (Cicero), MINISTER REGIS, "auxiliar, assistente de um rei” (Salústio), MINISTER REGNI, "auxiliar, assistente de um reino" (Justiniano), etc.

$\mathrm{Na}$ linguagem religiosa do paganismo foi usado como "ministro de um deus, sacerdote". Plausivelmente baseado aí, o termo passou, na linguagem cristã, a significar "servidor de Deus, do culto, do Evangelho", e, em seguida, principalmente entre os protestantes (séc. 16), veio a significar "pastor".

MINISTRO veio a ser empregado, nos tempos modernos, talvez por influência francesa, na linguagem da administração pública, como "membro de um ministério; ministro de Estado".

O fem. lat. MINISTRA era inicialmente apenas "serva, criada, escrava", e em seguida "serva de uma divindade, sacerdotisa", e, no Cristianismo, "diaconisa".

$O$ port. MINISTRO (lat. MINISTRUM), -A é de origem culta.

PANTERA - "mamifero carnivoro da familia dos Felídeos" - tem este nome de origem próxima no lat. PANTHERA e remotamente no gr. PÂNTHẼR. Não é composto de PĀN, "tudo", e THÉR, "animal", como erradamente interpretam ,mas forma helenizada do sânscrito PUNDARIKA. Em vista da terminação -KA, parece diminutivo, e o primeiro elemento talvez seja nome de cor PANDARAS, "amarelo esbranquiçado, fulvo".

PALHETE - O adj. PALHETE quer dizer "cla cor da pa lha", e em VINHO PALHETE qualifica um vinho, pouco carregado na cor. Usa-se também como subst. $\mathrm{E}$ o vinho tinto semelhante à cor de palha, isto é, pouco carregado. Parece que se trata de adaptação do fr. PAILLET, com o mesmo sentido.

ATROZ - O lat. ATROX, "cruel, desumano, doloroso, ctc.", originariamente valia "de aspecto negro", composto que é de ATER, ATRA, ATRUM, "negro; tenebroso", e de "OQU-, "com aspecto de", co-radical de "OCUS, OCULUM, "olho".

O elemento indo-europeu *OQU- chegou a -*OP- em grego AITHOPS, "de aspecto de fogo", donde "brilhante, ardente; violento", MELOPS, "de aspecto (da cor) de maçã", donde "áureo, louro, amarelo-ouro". O componente helênico é cognato de OPSIS (genit. ÓPSEÔS), "olho, vista".

$O$ lat. FEROX significou primevamente "de aspecto fero" ou, melhor, "de aspecto de fera", e UELOX é analógico de ambos, pois não podia equivaler a "de aspecto de velocidade". 
Do lat. ATROCE, FEROCE, UELOCE decorrem os semicultos port. ATROZ, FEROZ, VELOZ.

POLfCIA - Este vocábulo erudito veio-nos do lat. medieval POLITIA, por sua vez do gr. POLITEIA, assentado em PÓLIS, "cidade", que na antiguidade era um Estado.

Tanto no grego como no latim o termo vale o mesmo que "organização ou sistema politico, governo, Estado, democracia, poder do Estado, vida pública, Direito".

POLICIA, consoante Morais, é assim conceituado: "o governo, e administração interna da república, principalmente no que respeita às comodidades, i. c, limpeza, asseio, fartura de viveres e vestiaria, e à segurança dos cidadãos. No tratamento decente, a cultura, adorno, urbanidade dos cidadãos, no falar, no termo, na boa maneira". No plural: obras de curioso lavor manufaturas de luxo".

O termo POLfCIA foi universalizado pela Revolução Francesa (fr. POLICE).

-LENTO - O sufixo erudito port. -LENTO, -A, de adjetivos, assenta no lat. -LENTUS, -A, que exprime "provimento; intensidade". ExS.: SUCULENTO (SUCCULENTUS), CORPU. LENTO (CORPULENTUS), PURULENTO (PURULENTUS), SONOLENTO (SOMNOLENTUS), FECULENTO (FECULENTUS), FRAUDULENTO (FRAUDULENTUS), SANGUINOLENTO (SANGUINOLENTUS), VIOLENTO (UIOLENTUS), etc.

Todos os exemplos latinos tiveram por modelo UINOLENTUS (port. VINOLENTO), e ele, por sua vez, é um composto "UIN'OLENTUS, i. é, "que cheira (OLENS, OLENTIS) a vinho (UINUNi)" (Saussure, F. Stürmer).

E plausivel que, entre os primeiros analógicos, fossem UIOLENTUS e SUCCULENTUS. O primeiro, pela quase semelhança fônica com UINOLENTUS, e, certo, haveria de ter uma conotação humoristica pelo relacionamento semântico. E o segundo somente pela relação semântica entre UINUM e SUCCUS.

$\hat{E}$, pois, errado explicar -LENTO como o sufixo -ENTO precedido de um -L- "eufônico".

ESPIRITO - Do lat.. SPIRITUS recebemos ESPIRITO, palavra culta, ou melhor, como assevera JPiM, é um latinismo. De fato, e foi introduzido pela linguagem eclesiástica. A mais antiga abonação dada por aquele lexicógrafo refere-se a assunto religioso: "Todo crischão crea firmemente que huu soo e verdadeyro deus padre e fillu e spiritu sancto... (na trad. de FUERO REAL, séc. 13). 
E pré-historicamente um pós-verbal de SPIRARE, "soprar (o vento)", por sua vez de origem onamotópica (E. e M., B. Felice). Anteriormente o verbo era "SPISASE. De "soprar" passou a "exalar sopro" e "respirar", e deste vieram os sentidos figurados: "estar vivo; ser inspirado". De "soprar" decorre ainda o significado de "exalar odor".

SPIRITUS, inicialmente "sopro; ar; respiraçāo; aspiraçāo; exalação", graças ao gr. PNEUMA, "sopro", chegou a ter estes sentidos baseados nos do grego, i. é, "sopro divino, espirito divino, inspiraçāo" e dai "espirito, alma", e, na linguagem da Igreja, o "Espírito Santo".

A onomatopéia *SPIS é algo aproximada de ${ }^{*}$ SPU, "soprar", alicerce onomatopaico do gr. PSUCHE, (SPYCHE) "alma" (aportuguesado PSIQUE, da linguagem filosófica).

CHOUPO - O lat. POPULUS, nome de uma árvore, foi pronunciado (poppulus), talvez para distinguir de POPULUS. "povo", mas nāo permaneceu assim; foi mais tarde proferido (ploppus) e assim escrito, dando CHOPO e em seguida, com esquisita ditongação da tônica, CHOUPO.

No fr. veio a ser PEUPLE, chocando-se com PEUPLE, "povo", recorreu-se para a clareza, e chamou-se aquele POPLIER e PEUPLIER. Durante a Revoluçāo Francesa foi tido o choupo como a árvore do povo, e reverenciada. A confusão criou este fato.

CARNAVAL - O legítimo nome do carnaval em port. é INTRUDO (port. arc. ENTROYDO, ENTRUIDO), resultante do lat. ibérico INTROITUS, "entrada (da quaresma)". Em esp. ENTRUEJO, ANTRUEJO (esp. arc. ENTRUDO, ANTRUYDO), em leonês ANTRUDO, em galego ANTROIDO. Não obstante, em vista dos carnavais pomposos da França, o nome fr. CARNAVAL entrou em Portugal. O estrangeirismo está anotado pela primeira vez em 1542, segundo A. G. Cunha, e ENTRUDO tem documentaçāo datada de 1252, confirme J. P. Machado.

O fr. CARNAVAL (1285) é por sua vez adaptação do ital. CARNEVALE, graças aos pomposos folguedos de Veneza, Florença, Turim e Roma.

O carnaval tem origem pagã; remonta principalmente às festas em honra de Saturno, as saturnais. Comia-se, bebia-se, embriagava-se, jogava-se e dançava-se a valer. Na realidade havia um clima de euforia ficticia, próprio para desordens morais. De fato, entregavam-se todos a desenfreada licenciosidade e orgias.

Com o advento do Cristianismo não deixou o povo os folguedos herdados do paganismo, porém houve sensivel di- 
minuiçāo, em vista dos desregramentos e abusos energicamente condenados pela Igreja. Todavia ressurgiram com vigor no decorrer da segunda metade da. Idade Média e na Renascença.

Os festejos carnavalescos não tiveram espaço de tempo fixo, e variavam de lugar a lugar. Foi a Igreja que delimitou o fim dos festejos ao início da quaresma, i. é, a quarta-feira de cinzas.

Nos uiltimos dias o povo se entregava novamente a orgias, e, em vista do rigoroso jejum quaresmal, abusavam dos alimentos, especialmente da carne e de laticínios.

Muitas eram as denominaçōes do carnaval documentadas no latim medieval, todas de preocupação religiosa, quer dadas pela Igreja, quer pelo povo: CARNIS LEVAMEN, CARNIS PRIVIUM, CARNIS CAPIUM, CARNIS LEVARIUM, CARNIS LAXARIUM, CARNES TOLTAS, CARNES TOLLENDAS, totalmente sinônimos: "supressão ou privação da carne". Além disso, criaram-se locuçōes no infinitivo, sinonímicas: CARNEM LEVARE, CARNEM LIGARE, CARNEM LAXARE, CARNEM SECARE, i. é, "suprimir ou suspender a carne". Parece que se deve subentender em tais locuçōes TEMPUS: "tempo de suprimir a carne".

Entre outras designações na Itália sobressaiam estas: CARNASCIALE, CARNESCIALE, CARNASSALE, CARNESSALE, CARLASSARE, CARNELEVARE, CARNELEVALE, CARLAVARE, CARNALIVARI, CARNILIVARI, CARLEVAR.

Consoante A. Prati, "o italiano (toscano) CARNEVALE é abreviamento de CARNE LEVALE, por sua vez de CARNE LEVARE". Quanto à terminação -ALE é devida ao concorren. te CARNASCIALE, mais antigo que aquele. Todavia Paul Aebischer admite que a terminação se deve à analogia com NATALE.

Segundo Clemente Merlo, do lat. CARNELEVARE houve inicialmente CARNELEVALE e logo CARNEVALE. Para J. Corominas, a evolução teria sido provavelmente esta: CARLEVARE > CARNEVARE > CARNEVALE.

Além do português e do francês, o termo italiano foi acolhido pelo esp. CARNAVAL, ing. CARNIVAL, al. KARNEVAL.

Outras expressões latinas que tiveram voga - INITIUM, INCIPERE, SUSCIPERE, INTROITUS (já citado), todas sinonimicas: "inicio, entrada (da quaresma)".

A preocupação com o comer antes do grande jejum de 40 dias, em memória do jejum de Cristo, deu origem a vários nomes para o carnaval em diversos dialetos românicos, principalmente para os seus últimos dias: "os dias gordos" (em 
fr. JOURS GRAS), "tempo de carne", "os últimos dias", "o último dia", "o primeiro da quaresma", "a terça-feira gorda", etc. $O$ fr. MARDI GRAS criou o port. TERÇA-FEIRA GORDA.

PEDRA - Vem do lat. PETRA, "pedra, rocha", e por sua vez é empréstimo do gr. PÉTRA. O vocábulo genuíno do lat. é SAXUM (de que resultou o port. SEIXO).

Afirmam E. e M. que talvez haja sido empregado primeiramente na linguagem dos marinheiros. A favor disto é que tem igualmente o sentido de "escolho, recife". Bons escritores, no dizer dos mesmos, evitavam o seu emprego, mas devia ser corrente na linguagem popular, e inclusive acatado pela Vulgata, de acordo com a Versão dos Setenta (gr. PETRA), a traduzir o hebraico e arameu KEPHA', KEFA'. - Entre os romanos o pedreiro era designado STRUCTOR, "construtor, arquiteto". No lat. vuig., na base de PETRA, fez-se "PETRARIU, que através de PEDRAIRO, resultou PEDREIRO.

ISCA - O port. ISCA, "substância que se pōe no anzol para atrair peixe", tem proveniência no lat. ESCA, "alimentação; sustento; pasto".

Não está claro como a vogal inicial do lat. passou a I. Para JPM, o lat. ESCARE, "comer; usar isca", tem a vogal inicial não tônica, e assim deste verbo proveio o regressivo ISCA.

$O$ lat. ESCA originou-se de *ETSKA, anteriormente *EDSKA, composto da raiz "ED- (lat. ÉDERE, "comer") e do sufixo de diminutivo -S-KA. Portanto, primitivamente valia "comidinha". Igual formação tem o lat. POSCA, "bebida composta de água, vinagre e ovos", originado de "POT-S-KA, "bebidinha", da raiz "POT-, de POTARE, "beber". Paralelo: eslavo VODKA, primitivamente "bebidinha": VOD, "agua", e $-\mathrm{KA}$, suf. de dim.

CARO - O lat. CARUS (port. CARO), "querido, amado, benquisto; precioso, que custa muito", é aparentado ao irlandès arc. KARA, "parente", galês CAR, "amigo", CARA-, "amar", sânscr. TSHARU-, "caro; agrađável", letônio KAR-S, "desejoso".

Do lat. CARUS vem CARITAS, CARITATIS (port. CARIDADE), "amor, ternura, amizade; preço alto".

$\mathrm{Da}$ idéia de "querido, amado" passou-se à de "amante" $\mathrm{e}$ logo "adúltero" no gótico HOR-S, e no al., fem., HURE, "meretriz", e assim também no ing. WHORE.

Da mesma raiz, conforme Trombetti, é o gr. CHAIRO, "alegrar-se", CHARIS, "graça"; prazer; alegria; benevolência; 
respeito; beleza"; sânscr. HAR-, "alegrar-se"; osco-umbro HER-, "querer".

Ernout e Meillet não incluem acima o gr. e o osco-umbro, porém os fazem aliados ao lat. HORIOR, "fazer querer", e ao anglo-sax. GEORNE, "desejoso de" (al. GERN, "de boa vontade").

LONGINQUO - O adj. port. LONGINQUO, erudito, é do lat. LONGINQUUS. Compōe-se de LONGI, "longe", e de *IN. QUUS, "que mora, habita", co-radical de INQUILINUS, "habitante" (port. INQUILINO). O sentido é evidente: "que mora longe, distante; estrangeiro".

$O$ antônimo do anterior é PROPINQUUS (port. PRO. PINQUO, arc. PROPINCO), "próximo, vizinho". O port. PROPINQUOS quer dizer "parentes".

Também é composto: PROPE, "perto (de), junto (a)" e de "INQUUS.

IMBUIR - "Meter em um líquido, impregnar, embeber". $\mathrm{Da}$ onomatopéia "BU, "BUA, com que as crianças pedem água, fez-se, entre os romanos, o verbo BÚERE, "beber", o qual logo se arcaizou, facilitado por BfBERE. Ela serviu de base para o subst. BUA, "bebida", e para o composto UINIBUA, "bebedora de vinho". E com o prefixo IN-, denotante de movimento para dentro, criou-se IMBUERE, "embeber, impregnar, ensopar, banhar; penetrar, encher de", mas cujo verbo mudou de conjugação, para IMBUIRE, que justifica o port. e o esp. IMBUIR.

O sânscr. possui BU, AMBU(H), "água", e com repetição da consoante $B$ criou-se expressivamente BUMBA, "água", e deste BUMBITI, "beber".

A onomatopéia também se manifestou alhures, em fami-lias lingüisticas diferentes: suaile (bantu) MVUA, "chover", línguas papuanas (Nova Guiné) MBWA, "água", bororo BU, "chuva", BUBU-, "chover".

PROFETA - vocábulo erudito, introduzido nas línguas ocidentais pela Igreja. Trata-se do lat. PROPHETA, latinização do gr. PROPHETES, cuja forma também entrou para o léxico lat. - PROPHETES.

É composto de PRO', "antes, diante", e do radical de PHEMf, "dizer, anunciar". Literalmente "aquele que anuncia com antecedência". Paralelo semântico: lat. PRAEDfCERE, "predizer".

É cognato do segundo elemento gr. o subst. PHEME, "expressão; linguagem; opinião; fama", por sua vez aparen- 
tado ao lat. FAMA, "voz pública; reputação, fama", ao armênio BAN, "palavra", ao islandês arc. BUN, "oração", todos do proto-indo-europeu *BHA-M-, e co-radical do árabe FAMM, "boca", arameu PUMMA, "boca", do semítico *PA-M-.

DERRUBAR DERRIBAR - São verbos sinônimos: "deitar abaixo, o que está erguido" (Morais); demolir". Um nāo é variante de outro, embora foneticamente dê esta impressão.

DERRUBAR promana do lat. DERUBARE (U longo), mas não chegou à pranúncia (derubar) certamente pela consciência da composição (DE-RƯPERE), por se relacionar com o lat. RUPA, "rochedo, penedia; precipício" (forma documentada em Lúcio Apuleio, séc. $2^{\circ}$ ), em vez do clássico RUPES.

Segundo Cornu, Seelmann e outros, parece que o R-, inicial, era proferido como vibrante simples, como em AREIA, porém $\mathbf{S}$. S. Neto acha que se pode explicar o R. vibrante múltipla $(=R R)$ "por hábitos articulatórios das línguas préromanas" (substrato). Todavia, em inscrições do fim da República Romana, encontra-se, p. ex., ARRESPEX, em vez de HARUSPEX.

J. P. Machado apresenta DI(R)RUPARE e DE(R)RUPA$R E$, que devem ser explicados como havendo duas pronúncias ( $R$ e $R R$ ).

Meyer-Luebke postula um lat. vlg. "DISRUPARE, cuja forma nāo é acolhida por J. Corominas, "porque nāo se trata de destruir um penhasco, senāo "lançar de (lat. $\mathrm{DE}$ ) um penhasco". Ademais é insólita a assimilação do $\mathrm{S}$ ao $\mathrm{R}$.

De DERUPARE saiu o ital. DIRUPARE (DIRUPARSI, arc., "precipitar-se"), mas o fr. arc. DESRUPER, DESRUBER deve, contudo, ter a base em "DISRUPARE. Daquele provém o esp. arc. DERRUBAR, o qual passou a DESRUBAR por mais de um motivo.

Quanto a DERRIBAR, se bem que A.A. Cortesão e Nascentes admitam um lat. vlg. "DERIPARE, a melhor explicação é a de que se trata de formação vernácula, e assim também o esp. DERRIBAR.

Criou-se, então, DE-RIBA-AR, "fazer cair de uma escarpa, etc. "Corominas no BREVE DIC. ETIM. DE LA LENGUA CASTELLANA acha possivel derivar de RIBA o" esp. DERRIBAR, com os mesmos sentidos do port. DERRIBAR.

Formaçōes paralelas: O esp. PENA, "penedo, rocha", fez DEPENAR, "precipitar algo de uma penha", o qual passou ao port. DESPENHAR.

Do lat. MOLES, "mole, massa; massa de pedra, etc.", formou-se DEMOLIRI, DEMOLIRE, "lançar algo do alto de uma rocha", depois "demolir" (port. DEMOLIR, erudito). 
MiSTICO - O gr. MYSTIKóS, adj., "relativo a mistério; misterioso, secreto", foi latinizado MYSTICUS (port. MíSTICO, erudito), e, na linguagem cristã, eclesiástica, além dos significados acima, veio a idéia também de "sagrado" e, ainda, "simbólico" (p. ex., MYSTICA SIGNIFICATIO, "significaçāo mistica", MYSTICUS NUMERUS, "número mistico"), e, como subst., aplicou-se a "sacerdote do judaísmo".

O port. MiSTICO, subst., veio a designar "pessoa de vida contemplativa e espiritual", e assim em outras linguas.

ÜVULA - "apêndice cônico na parte posterior do véu palatino" (termo culto) é o lat. UUULA, dim. de UUA, "uva", pela semelhança que tem esse apêndice com um bago de uva. Todavia, o lat. é decalque do gr. STAPHULION (STAPHYLON), dim, de STAPHULE', "uva".

Popularmente, a úvula, também por semelhança, é denominada CAMPAINHA.

INTERVALO - Do lat. INTERUALLUM decorre o port. INTERVALO. O lat. era termo da linguagem militar: "espaço entre duas paliçadas do acampamento". Compōe-se de INTER, "entre", e UALLUM, "paliçada, trincheira, estacada". Era obstáculo para defesa militar. O segundo componente nada tem com o lat. UALLIS, "vale, concavidade".

Outros sentidos decorrentes: INTERUALLUM: "espaço; distância; demora; tardança; espaço de tempo (dai "espaço de tempo para repouso" e "repouso").

Do port. INTERVALO fez-se INTERVALAR, "dispor com intervalos; entremear; alternar; estar disposto por intervalos".

ACOSSAR - Verbo criado no tempo da pirataria; significa "perseguir navios para roubos, piratear". Formou-se na base de COSSO, hoje arcaizado, "ato de atacar navios inimigos para roubar". COSSO deriva do lat. CURSU, "ato de correr, corrida; viagem por mar" (cognato de CÚRRERE, "correr").

COSSO já se acha registrado em 1433: “...entende de armar alguus nauyos pera andarem de cosso no estreito..." (JPM, de acordo com DESCOBRIMENTOS PORT., I, 274).

Pelo contacto com os italianos entrou no port. CORSO, "ato de perseguir o inimigo por mar", da mesma origem latina.

De COSSO fez-se COSSAIRO, "pirata" (documento mais añt. no séc. 13 , segundo $\Lambda$. G. Cunha). Por influência erudita é que se tem CORSARIO. JPM admite haver duas influências: 
1) O fr. ant. COSSAR (documentável em 1200), donde COSSAIRO, com -AIRO analógico; 2) talvez do ital. COSSARO, com o sufixo -ARIO, analógico.

No port. arc. a locução COSSARIO DE TODA ROUPA significava "o que rouba a inimigos e a amigos" (Morais). "ROUPA, "coisa roubada por pirata".

ANJO - Do lat. ANGELU > ANGEO > ANJOO > ANJO. O gr. ANGELOS, "mensageiro", passou na linguagem bíblica a significar "mensageiro celeste, mensageiro de Deus", e assim aproveitado no latim ÁNGELUS. Segundo etimologia proposta por A. Trombetti, o gr. ANGELOS é forma dissimilada de *ALGE-LO-, e aparentada ao lat. LEG-A-RE, "enviar em embaixada, enviar alguém por embaixador".

$A$ raiz semitica que se alia com o indo-europeu (*LEG-, "ALGE-) é o segundo elemento de "MA-LAK, "enviado", donde o hebreu MAL'ĀK, árabe MALAK, "enviado, mensageiro; anjo", etc. Sem o prefixo participial MA-, tem-se o ár. ALAK, "ser mensageiro".

VIRTUDE - O lat. UIR (genit. UIRI) quer dizer "homem" sob o aspecto da masculinidade, da virilidade, e um dos seus derivados é UIRTUS, UIRTUTIS, originariamente "força, robustez, vigor" e dai "energia, coragem, qualidades morais, disposição de fazer o bem, prática do bem; caráter; perfeição moral; mérito".

O lat. UIRTUS é derivado de UIR, "homem", como SENECTUS, "velhice", e IUUENTUS, "juventude", foram derivados respectivamente de SENEX, "velho", e IUUENIS, "jovem".

O lat. UIRTUS possui, como formação paralela, o esp. HOMBREDAD (donde o port. HOMBRIDADE), assentado em HOMBRE, "homem". HOMBRIDADE quer dizer "aspecto varonil; dignidade; integridade de caráter; nobreza de alma".

O port. VIRTUDE é continuação do acus. lat. UIRTU$\mathrm{TE}[\mathrm{M}]$.

Deve-se ao Cristianismo o emprego cada vez maior do termo, quer em latim, quer em português (cp. VIRTUDES MORAIS e VIRTUDES TEOLOGAIS).

Para a idéia de virtude como "probidade", o gr. tem ARETE, cognato de ARSÉN. "macho". ARETE exprime também "capacidade, habilidade".

Em al., "virtude" é TUGEND, co-radical de TUGEN, "valer, ser útil, ser bom", por sua vez aparentado ao gr. TUCHE, "sorte, fortuna, dita, êxito". 
Os padres jesuitas que cristianizaram os tupis do litoral brasileiro, deram mais de um nome a virtude: EKOKATU, compostc de EKO, "costume", e KATÚ, "bom". Virtude como bondade natural é ANGATURAMA, i. é, ANGA, "alma", KA. TU," "boa", e AMA "costume". EKOPORANGA, "costume belo", e, finalmente, KARAfBA, "homem-santidade; força de espirito".

\begin{abstract}
The Author deals with news etymologies to be included in a future edition of the DICIONARIO DE ETIMOLOGIAS DA LfNGUA PORTUGUESA. The entries are: CONSUL, PESSOA, LUZIR, BRANCO, LADAINHA, PONEI, EXPLI. CAR, FELINO, LITURGIA, FEIJAO, FIL(O)-, RUBEOLA, PRUDENTE, ATACADO, ALFACE, VICIO, SUFRAGIO, PRETO, SACRARIO, TREMER, OSCULO, PARPALHAÇA, CLERO, PREMIO, CASTO, LATIM, GUAI!, ARTE, CAVALO, GUERRILHA, INSTRUMENTALISMO, BATIZAR, ESTRADA, PIPOCA, MINISTRO, PANTERA, PALHETE, ATROZ, POLICIA, -LENTO, ESPIRITO, CHOUPO, CARNAVAL, PE. DRA, ISCA, CARO, LONGINQUO, IMBUIR, PROFETA, DERRUBAR, DERRIBAR, MISTICO, UVULA, INTERVALO, ACOSSAR, ANJO, VIRTUDE.
\end{abstract}

